\title{
A 3D Approach for THD Lubrication in Tilting Pad Journal Bearing-Theory and Experiment
}

Bizarre, L.; Andersen, T. B.; Daniel, G. B.; Santos, I. F.; Cavalca, K. L.

Published in:

Tribology Transactions

Link to article, DOI:

10.1080/10402004.2019.1664686

Publication date:

2020

Document Version

Peer reviewed version

Link back to DTU Orbit

Citation (APA):

Bizarre, L., Andersen, T. B., Daniel, G. B., Santos, I. F., \& Cavalca, K. L. (2020). A 3D Approach for THD Lubrication in Tilting Pad Journal Bearing-Theory and Experiment. Tribology Transactions, 63(1), 120-132. https://doi.org/10.1080/10402004.2019.1664686

\section{General rights}

Copyright and moral rights for the publications made accessible in the public portal are retained by the authors and/or other copyright owners and it is a condition of accessing publications that users recognise and abide by the legal requirements associated with these rights.

- Users may download and print one copy of any publication from the public portal for the purpose of private study or research.

- You may not further distribute the material or use it for any profit-making activity or commercial gain

- You may freely distribute the URL identifying the publication in the public portal 


\section{A 3D approach for THD lubrication in tilting pad journal bearing - Theory and Experiment}

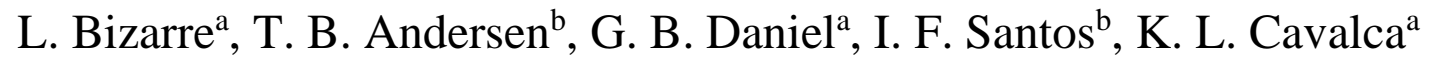

${ }^{a}$ Department of Integrated Systems, University of Campinas, Campinas, São Paulo, Brazil

${ }^{b}$ Department of Mechanical Engineering, Technical University of Denmark, KogensLyngby, Denmark

E-mail addresses: leticia.bizarre@ @em.unicamp.br (L. Bizarre),

thor.bayer@hotmail.com (T. B. Andersen), gbdaniel@ fem.unicamp.br (G. B. Daniel), ifs @ mek.dtu.dk (I. F. Santos), katia@fem.unicamp.br (K. L. Cavalca). 


\section{A 3D approach for THD lubrication in tilting pad journal bearing - Theory and Experiment}

The study of rotating machines stands out in the context of systems and structures due to the significant number of typical phenomena that may be present during the operation of such equipment. Rotating systems play an important role in industrial environments, with a wide range of application, namely: pumps, turbines, generators and compressors, turbochargers, among others. Given this context, tilting pad journal bearings (TPJB) can offer considerable stability to the rotor system due to its damping and stiffness characteristics, especially under high rotation speeds, while journal bearings with fixed geometry may be subjected to fluid-induced instability. Consequently, thermal effects are significant in rotating machines to evaluate the behavior of hydrodynamic bearings due to the increase in shear effects in the lubricant caused by the rotation speed, leading to expressive temperature increase under specific operational conditions and therefore, significant changes in lubricant viscosity. These effects may influence the dynamic characteristics of bearings, affecting the dynamic response of the entire system. Under this perspective, a specific test rig was designed to perform the characteristic uncoupled motion of the shaft when supported by this kind of bearings. Experimental tests were directly compared with numerical models showing promising results. Besides, the THD lubrication was numerically solved by finite volume method, considering an approach for $3 \mathrm{D}$ THD model and the pivot flexibility.

Keywords: tilting pad bearing, numerical model, thermal effects, experimental tests, pivot flexibility. 


\section{Nomenclature}

THD Thermohydrodynamic

BC Boundary Condition

TPJB Tilting pad journal bearing

LOP Load on pad

FVM Finite volume method

$\alpha$

Pad angle deflection $\left[{ }^{\circ}\right]$

$\beta_{s} \quad$ Pad arc length $\left[{ }^{\circ}\right]$

$\varepsilon \quad$ Eccentricity ratio [-]

$\mu \quad$ Oil dynamic viscosity [Pa.s]

$v_{\text {oil }} \quad$ Oil kinematic viscosity [ctS]

$\rho \quad$ Density $\left[\mathrm{Kg} / \mathrm{m}^{3}\right]$

$\omega \quad$ Journal angular velocity $[\mathrm{rad} / \mathrm{s}]$

$\varphi \quad$ Angle between the inertial system and the auxiliary system for the $\mathrm{n}$-th pad $\left[^{\circ}\right]$

$\Phi \quad$ Viscous dissipation $\left[\mathrm{Kg} . \mathrm{m}^{2} / \mathrm{Pa} . \mathrm{s}^{3}\right]$

$C_{f} \quad$ Specific lubricant oil heat $[\mathrm{J} / \mathrm{Kg} \mathrm{K}]$

$C_{p} \quad$ Pad machined-in radial clearance $[\mathrm{m}]$

$h_{0} \quad$ Assembled radial clearance of the bearing $[\mathrm{m}]$

$e \quad$ Eccentricity $[\mathrm{m}]$

$f_{\text {static }} \quad$ Static force on frame extremity $[\mathrm{N}]$

$f_{\text {pivot }} \quad$ Reaction force from pivot point $[\mathrm{N}]$

$h \quad$ Oil Film thickness [m]

$h_{s} \quad$ Pad thickness [m]

$k_{f} \quad$ Thermal conductivity of the lubricant oil $[\mathrm{W} / \mathrm{mK}]$

$K_{\text {pivot }} \quad$ Pivot point stiffness [N/m]

$L \quad$ Bearing length $[\mathrm{m}]$

$l_{1} \quad$ Distance to journal center measured from $O_{1}[\mathrm{~m}]$

$l_{2} \quad$ Distance to end of the frame measured from $O_{1}[\mathrm{~m}]$

Mass of journal and frame $[\mathrm{Kg}]$ 


$\begin{array}{ll}m_{p} & \text { Preload factor [-] } \\ O_{1} & \text { Frame rotational point [-] } \\ O_{2} & \text { Journal rotational point [-] } \\ O P & \text { Pivot center of rotation [-] } \\ O S & \text { Pad center [-] } \\ O E & \text { Shaft center [-] } \\ P & \text { Pressure in the oil film between journal } \\ R & \text { and pad [Pa] } \\ R_{S} & \text { Journal radius [m] } \\ S & \text { Pad radius [m] } \\ t & \text { Sommerfeld number [-] } \\ T & \text { Time [s] } \\ T_{r e p l a c e m e n t} & \text { Replacement temperature }\left[{ }^{\circ} \mathrm{C}\right] \\ T_{\text {shaft }} & \left.\text { Shaft temperature [ }{ }^{\circ} \mathrm{C}\right] \\ U & \text { Journal surface velocity [m/s] } \\ u, v, w & \text { Linear velocities in } \mathrm{x}, \mathrm{y} \text { and z-direction } \\ W & \text { [m/s] } \\ X, Y, Z & \text { Load on bearing [N] } \\ x, y, z & \text { Inertial system [-] } \\ x^{\prime}, y^{\prime}, z^{\prime} & \text { Local coordinates system [-] } \\ & \text { Auxiliary coordinate system fixed to } \\ & \end{array}$

\section{INTRODUCTION}

Investing in energy generation sources is mandatory when seeking to improve the productivity of the majority fields of industry. This industrial environment may demand significantly higher rotational speeds to boost the productive system. Consequently, considering rotational systems, lubricated bearings model and its thermal effects become critical in this context. The growing demand for increasing the rotational speed of machines leads to the study of multilobular bearings, which compensate for the limitations of cylindrical bearings imposed by the phenomenon of induced fluid 
instability at high rotation speeds. Pinkus [1] published a numerical solution for trilobular bearings, a type that was developed to avoid this kind of instability. Although the multilobular geometry delayed the induced fluid instability phenomenon, it will still occur at higher rotational speeds. Unlike fixed geometry bearings, tilting pad bearings show better stability conditions due to the independent angular movement of the segments, which practically mitigates the fluid-induced vibration phenomena. In addition, some concerns on the lubricant behavior when subjected to high rotation speeds led to researchers' efforts to estimate the thermal effects on hydrodynamic cylindrical bearings, later expanded to multilobular and tilting pad bearings [2-5].

Considering this perspective, Dowson [6] became a milestone for the thermohydrodynamic analysis of lubricated bearings. The research presented the generalized Reynolds equation, considering the variation of viscosity and density (for compressible fluids) of the lubricant in both circumferential and radial directions, considerably reducing the number of simplified assumptions in previous thermal analyses of hydrodynamic bearings. Afterward, Dowson et al. [7] expanded the model to a two-dimensional thermohydrodynamic analysis by solving the generalized Reynolds equation, the energy and the conduction equations. This work showed that temperature gradients can be neglected in the axial direction in relation to radial and circumferential directions.

In 1986, Heshmat \& Pinkus [8] studied the mixing mechanism at the bearing oil inlet, obtaining experimental results and theoretical equations for the mixing temperature as a function of the bearing parameters. 
In the work of Han \& Paranjpe [9], the finite volume method was used to analyze the thermohydrodynamic bearings, improving the approach of the numerical model to the physical problem, providing better accuracy and convergence of the results from the continuity equation. Another important contribution was to observe the significant influence of temperature boundary conditions on the numerical solution, indicating the need for care and refinement in those assumptions.

In 2011, Dimond et al. [10] published a review on the state of the art of tilting pad journal bearings theory over the last 50 years. The paper discusses and proposes experimental procedures based on the development of thermohydrodynamic, thermoelastohydrodynamic and bulk-flow modeling of tilting pad bearings.

A thermohydrodynamic model was also developed by the finite difference method to solve Reynolds' equation coupled with the energy equations found in Santos [11] to study the thermal effects on tilting pad bearings. The study shows that the design of tilting pad bearings by isothermal models resulted in an oversized component and the estimated pressure distribution was significantly higher than that obtained by a thermohydrodynamic model.

Later, Santos and Nicoletti [12] presented the thermal effects on hybrid tilting pad bearings, analyzing the injection pressure and the position of the holes, as well as their influence on the bearing temperature, since these parameters are related to the oil inlet in the bearing. Regarding the models proposed by Santos [11] and Santos and Nicoletti [12], Daniel and Cavalca [13, 14] contributed by considering the temperature distribution over the lubricant film thickness, also evaluating the thermal effects. Stiffness and damping coefficients were calculated from both hydrodynamic and 
thermohydrodynamic lubrication models, verifying the influence of thermal effects on the dynamic characteristics of tilting pad bearings. Lubrication conditions, such as the minimum film thickness, were also evaluated.

Varela [15] incorporates improvements in the mechatronic system that controls the servo oil injection valves in the test system developed by Nielsen [16] and obtained a theoretical model considering TEHD lubrication and modeled the hydraulic system associated with the controllable segmented bearing, comparing its results experimentally, evaluating the static and dynamic behavior of the bearing operating actively due to the hydraulic control. The results obtained in their work showed an improvement in the heat exchange between fluid and bearing segments due to the injection of replacement fluid and their numerical results for temperature, pressure and equilibrium position profiles were consistent with the experimental results.

Considering the pivot flexibility, Nilsson [17] provided a study about the influence of pad flexibility on the dynamic performance of tilting-pad bearings. The pad flexibility (related to the pad flexibility relative to the pivot) results in a change in the surface curvature of the pad. San Andrés et al. [18, 19] accomplished a review of influence of the pivot flexibility on the bearing statics as well as their performance (e.g., oil film temperature, minimum film thickness, eccentricity, etc.) and their dynamic coefficients and the numerical results were compared with the tests shown by Gaines [20]. Suh and Choi [21] studied the design of the pivot and the effects of angular misalignment in the three directions of the segment in the characteristics of the tiltingpad bearing. They considered the THD lubrication model and employed the motion in the three directions of the segment and altered the oil film thickness expression, employing the axial variation of the film gap with the pad inclinations. The work of 
Conti et. al [22] developed a model and an experimental validation of a quasi-3D TPJB model, analyzing the fluid dynamics, the rotor dynamics of the system and their complex interactions. A heuristic law was proposed in order to predict the TPJB fluid dynamical characteristics taking into account the coupled effects.

This research is within the context of experimental validation of tilting pad thermohydrodynamic numerical model when considering the discretization in the film thickness direction. Its contribution also involves the pivot flexibility influence on the geometric center of the shaft (locus) and on the temperature distribution while under different operational conditions of load and rotation speed, being experimentally verified on a specific test bench designed to on pad loaded tilting pad bearings [23, 24]. The thermohydrodynamic numerical model was applied, providing numerically and simultaneously evaluating pressure and temperature distribution in the oil film. The velocity profile comes from the pressure distribution obtained by the Reynolds' equation solution [25], which allows determining viscous dissipation and, consequently, the temperature distribution on the bearing wall through the integrated solution of the Energy Equation in the numerical processes.

The main contribution of the present work is the application of a specific test rig designed to isolate the vertical direction effects, allowing the THD analysis of each pad separately, which takes into account the oil film thickness direction on the energy equation and the influence of pivot flexibility.

\section{MATERIALS AND METHODS}

\section{Numerical model description}

The tilting pad journal bearing (TPJB) studied in this research presents the geometrical 
features outlined in Figure 1, with two pads supporting the shaft. Its operation condition is load-on-pad (LOP). The numerical model can simulate specific experimental tests for comparisons with the test rig dedicated to TPJB tests, presented by Andersen [24], Varella [15] and Nielsen [16], and described in the following sections. The geometrical terms labeled on Fig. 1 are $R$ the journal radius, $R_{s}$ the pad radius, $h_{0}$ the assembled radial clearance of the bearing, $h_{s}$ the pad thickness, $\alpha$ the pad tilt angle deflection, $\varphi$ the angular position of the pivot, $L$ the pad length and $\beta_{S}$ the pad angular span. Besides the geometrical properties, the reference systems to be applied during the modeling description are essential (Figure 1): $O P, O S$ and $O E$ that are, respectively, the pivot center of rotation, the pad center radius and the shaft center radius, $X, Y, Z$ is the inertial system, $x, y, z$ the local coordinates system and $x^{\prime}, y^{\prime}, z^{\prime}$ the auxiliary coordinate system fixed in the pad.

[Figure 1]

Other fundamental parameters for tilting pad bearing analysis are the radial clearance and the preload. The nominal radial clearance of the bearing $C_{p}$ is defined as the difference between the pad radius and the journal radius:

$$
C_{p}=R_{s}-R
$$

Considering the nominal radial clearance and the assembled radial clearance of the bearing $\left(h_{0}\right)$, the preload factor can be determined as:

$$
m_{p}=1-\left(\frac{h_{0}}{c_{p}}\right)
$$

Figure 1 (c) represents the distance from the journal center to the bearing center (eccentricity, $e$ ). The dimensionless form of this parameter (eccentricity ratio, $\varepsilon$ ) is 
given by the ratio with the actual radial clearance $h_{0}$.

Reynolds' classic equation, widely used to describe the theoretical basis of hydrodynamic lubrication [25], is given by Equation 3, in its THD form, and allows to find the pressure distribution in the region of contact between the lubricated bodies to be calculated. The term $P(x, y)$ is the pressure, $\mu$ is the viscosity, $h$ is the oil film thickness, $\omega$ is the rotational speed, $t$ is time and $x$ and $z$ the Cartesian coordinates.

$$
\frac{\partial}{\partial x}\left(F_{2} \frac{\partial P}{\partial x}\right)+\frac{\partial}{\partial z}\left(F_{2} \frac{\partial P}{\partial z}\right)=U \frac{\partial}{\partial x}\left[h-\frac{F_{1}}{F_{2}}\right]+\frac{\partial h}{\partial t}
$$

With: $F_{1}=\int_{0}^{h} \frac{y}{\mu} d y, F_{2}=\int_{0}^{h} \frac{y}{\mu}\left(y-\frac{F_{1}}{F_{0}}\right) d y$ and $F_{0}=\int_{0}^{h} \frac{1}{\mu} d y$.

The expression to describe the oil film thickness, Equation 4, is fundamental and relates geometric parameters, the angular displacement of the pad and shaft eccentricity (Santos e Russo [26]). The terms $x_{S}$ and $y_{S}$ are the positions of the shaft in the local reference system $(x, y)$.

$$
h(\beta)=R_{S}-R-\left\{\sin (\beta)\left[y_{S}+\alpha\left(R_{S}+h_{S}\right)\right]+\cos (\beta)\left(x_{S}+R_{S}-R-h_{0}\right)\right\}(4)
$$

Pressure distribution evaluation occurs concurrently with the temperature in an iterative process. Thus, the energy equation is applied to obtain the temperature distribution in the bearing oil film. This research assumes an approach of no heat transfer through the axial coordinate. Based on Cameron [27], this effect can be neglected in relation to the radial and circumferential directions of the system. Therefore, Equation 5 gives the energy equation in which Equation 6 is the viscous dissipation:

$$
\rho C_{f}\left(u \frac{\partial T}{\partial x}+v \frac{\partial T}{\partial y}\right)=k_{f}\left(\frac{\partial^{2} T}{\partial x^{2}}+\frac{\partial^{2} T}{\partial y}\right)+\mu \Phi
$$




$$
\Phi=2\left[\left(\frac{\partial u}{\partial x}\right)^{2}+\left(\frac{\partial v}{\partial y}\right)^{2}\right]+\left(\frac{\partial u}{\partial x}+\frac{\partial v}{\partial y}\right)^{2}+\left(\frac{\partial w}{\partial x}\right)^{2}+\left(\frac{\partial w}{\partial y}\right)^{2}
$$

where, $\rho$ is the density, $u, v$ and $w$ the linear velocities in $\mathrm{x}, \mathrm{y}$ and $\mathrm{z}$ directions, respectively, $\mu$ is the oil film viscosity, $T(x, y)$ is the temperature distribution and $\Phi$ is the viscous dissipation of the fluid film.

The energy equation is a function of $\mathrm{x}$ and $\mathrm{y}$ coordinates. The numerical method considers the fluid film discretization in all three directions ( $\mathrm{x}, \mathrm{y}$ and $\mathrm{z}$ ) and, for each position of $\mathrm{z}$, the equations are integrated (Figure 6). The direction of the oil film thickness is thus considered in numerical modeling, as proposed by Daniel \& Cavalca $[13,14]$. As the heat transfer in axial direction barely influences the temperature distribution, in this case, the fluid film is then discretized in the z-direction (Figure 6(a)), disregarding the flux between $x-y$ meshes in this direction.

Furthermore, the energy equation and the relation viscosity-temperature needs to be defined. Oil viscosity is highly dependent on oil temperature and the relation can be expressed by Walther's formula [28, 29]:

$$
\Phi \log \left[\log \left(v_{\text {oil }}+0.6\right)\right]=A-B \cdot \log \left(T_{\text {oil }}\right)
$$

where $v_{o i l}$ is the kinematic viscosity and A and B are two oil-specific constants. It is important to highlight that $v$ unit is $\mathrm{cSt}$ and $T_{\text {oil }}$ must be in ${ }^{\circ} \mathrm{C}$. This research utilizes an ISO VG22 lubricant with constants $\mathrm{A}$ and $\mathrm{B}(\mathrm{A}=23.16$ and $\mathrm{B}=3.84)$.

The energy equation requires the velocity components in the lubricant oil between pads and shaft. Dowson [6] (Equations 8-10) obtained these components from the Navier-Stokes equation and the continuity equation. Applying the boundary 
conditions of the hydrodynamic bearing in the Navier-Stokes equation, the velocities in the axial $(w)$ and circumferential $(u)$ directions can be determined and combined in the continuity equation to obtain the radial velocity $(v)[27]$ :

$$
\begin{gathered}
u=\frac{\partial P}{\partial x} \int_{0}^{y} \frac{y}{\mu} d y+\left(\frac{U}{F_{0}}-\frac{F_{1}}{F_{0}} \frac{\partial P}{\partial x}\right) \int_{0}^{y} \frac{1}{\mu} d y \\
w=\frac{\partial P}{\partial z} \int_{0}^{y} \frac{y}{\mu} d y-\left(\frac{F_{1}}{F_{0}} \frac{\partial P}{\partial z}\right) \int_{0}^{y} \frac{1}{\mu} d y \\
v=-\int_{0}^{y}\left(\frac{\partial y}{\partial x}+\frac{\partial w}{\partial z}\right) d y
\end{gathered}
$$

Finally, the bearing equilibrium equations presented by Daniel \& Cavalca [13, 14] relate the forces in $y$ and $x$ directions, the rotations of the pads around the pivots and the deformation of each pivot. Equations 11-16 contain the forces equilibrium made for the tilting pad bearing system. The sub-index $m_{1}$ and $m_{2}$ are representations of the upper pad and lower pad, respectively, $N$ is the number of pads, $j$ represents the $\mathrm{j}$-th pad and $W_{g}$ is the journal weight.

$$
\begin{gathered}
F_{x}=\sum_{1}^{N} F_{x m} \cos \left(\varphi_{j}+\alpha_{j}\right) \\
F_{y}-W_{g}=\sum_{1}^{N} F_{x m} \sin \left(\varphi_{j}+\alpha_{j}\right)-W_{g} \\
F_{y m_{1}}\left(R_{s}+h_{s}\right)=0 \\
F_{y m_{2}}\left(R_{s}+h_{s}\right)=0 \\
F_{x m_{1}}=K_{\text {pivot }, 1} \delta_{m 1} \\
F_{x m_{2}}=K_{\text {pivot }, 2} \delta_{m 2}
\end{gathered}
$$




\section{Pivot Flexibility}

Each pad tilts on a pivot, which is centered in the mid-span of the pad in this case. The material used in the pivot is steel, providing flexibility to the whole system and changing the fluid film thickness. The computational model needs to contemplate this flexibility to better represent the real tilting pad journal bearing. Figure 2 shows the scheme to include pivot flexibility $\left(K_{\text {pivot }, 1 / 2}\right)$ into the tilting pad bearing subsystem. The deformation derived from the pivot stiffness is included as an additional term in the oil film thickness, as shown in Equation 17. This modification is automatically transferred to the complete model and equilibrium equations during the iterative process to solve the complete system of equations.

[Figure 2]

$$
h(\beta)=R_{S}-R-\left\{\sin (\beta)\left[y_{S}+\alpha\left(R_{S}+h_{S}\right)\right]+\cos (\beta)\left(x_{S}+R_{S}-R-h_{0}\right)\right\}+\delta_{\text {pivot }}(17)
$$

\section{Numerical method}

The finite volume method (FVM) is applied to solve Reynolds' and Energy partial differential equations because it is not possible to obtain their full analytical solution. The method showed by Patankar [30] considers a non-uniform mesh to model the fluid film between pads and shaft. Therefore, a coordinate transform is required [30] to convert a non-uniform mesh (physical domain) into a uniform (numerical) domain as represented in Figure 3 (a).

[Figure 3]

An iterative process solves, simultaneously, the system of equations composed by Reynolds' Equation, the velocities fields, the viscosity equation, the Energy Equation, 
and equilibrium forces. The method to solve the linear systems of equations was the Gauss-Seidel method. Figure 4 contains the flowchart of the numerical process to solve the proposed tilting pad model used in the thermohydrodynamic analysis. The NewtonRaphson method is applied to solve the equilibrium system and for each value estimated, a complete loop indicated in Figure 4 is evaluated.

The first step is used to estimate the temperature distribution applying the oil boundary conditions (Figure 3 (b)) and the first viscosity field of the oil film. Following, the pressure distribution is calculated through Reynolds' equation by applying the FVM and the convergence of the solution was obtained through the GaussSeidel method. The following step is to calculate the velocity profiles and determine the new temperature using the energy equation (FVM is also applied with the Gauss-Seidel Method). With the new determined temperature field, a comparison is made with the previous estimation and the stop criterion is tested (in this research, the stop criterion is $1.10^{-5}$ comparing the global error for each iteration) until convergence. Figure 6 (a) provides an integration scheme applied to the energy equation that made steps in $\mathrm{z}$ (for $Z_{n}$ points) direction for each mesh $x \times y$; thus, considering the radial direction to evaluate the effects of lubrication on the bearing behavior.

[Figure 4]

To properly determine the number of volumes and simultaneously improve time consumption and results, a convergence test was conducted. Figure 5 (a) and (b) contain the results varying the number of volumes versus the processing time (a) and the eccentricity ratio (b) in the y-direction. Thus, it can be noted that the number of volumes with the best performance was $N x=40, N y=40$ and $N z=40$. 
[Figure 5]

[Figure 6]

Finally, the last step of the numerical description is choosing the boundary conditions (BC). Figure 3 (b) contains a scheme to represent the boundary conditions division. The oil film surface in contact with the shaft (represented by 2) is considered with a prescribed temperature equal to the shaft temperature. In the inlet face (represented by 1) of the pad, a mixing region is calculated by Equation 18, represented by Figure 6 (b). The outlet face of the pad (represented by 3 ) and the surface of contact between pad and oil (represented by 4), are considered adiabatic boundary conditions due to the minimum heat transfer that occurs in these faces.

$$
\begin{gathered}
T_{\text {mixture }}=\left[\left(T_{\text {NextPad }} \cdot Q_{\text {NextPad }}\right)+\left(T_{\text {Replacementoil }} \cdot Q_{\text {Replacementoil }}\right)\right] /\left(Q_{\text {NextPad }}+\right. \\
\left.Q_{\text {Replacementoil }}\right)
\end{gathered}
$$

Particularly, the tilting pad bearing is generally designed to provide positive pressure distributions in each pad, which can be guarantee by the preload or even by the direct oil feeding in each pad independently. In this way, the cavitation effects are not relevant in this kind of bearing, since we have no regions with pressures that behave below atmospheric pressure.

\section{Experimental test rig}

Regarding the validation of the numerical model proposed here, a test rig dedicated to testing tilting pad journal bearings is applied, at DTU in Lyngby, Denmark. The complete data about the test rig and its design are presented in Andersen [24], Varela e Santos [11] and Nielsen [16], providing information about its sensors, design and 
manufacturing. Figures 7 and 8 present a photo and a scheme of the assembled test rig, respectively. The rig enables the measurement of shaft displacements and, consequently, the eccentricity and temperature data on the middle of the pad. Thus, this research compares the experimental data obtained by Andersen [24] with the theoretical model developed in Bizarre's Ph.D. dissertation [31].

[Figure 7]

[Figure 8]

From the diagram in Figure 8, it is possible to note that the external load is applied at the end of the arm. Displacement sensors measure at points near to the shaft center and at the arm end. The system contains two oil inlets on the bearing sides that allow oil injection for lubrication of the two pads (indicated by the number (20) in Figure 7).

Table 1 presents the dimensions and properties of the experimental setup, bearing, pivot and lubricant oil applied during the experimental tests and numerical simulations (data presented in Andersen [24] and Daniel \& Cavalca [13, 14]). [Table 1]

The scheme presented in Fig. 8 outlined the fixed bearing position in the x-direction on the test-rig and the free possibility of movement in the y-direction. This configuration was designed to better represent the decoupled directions $\mathrm{x}$ and $\mathrm{y}$, characteristic of tilting-pad bearings. The model developed has both directions decoupled and the specific test-rig applied during this work allows to evaluate de bearing model using this configuration in $\mathrm{x}$ and $\mathrm{y}$ directions. In this way, the application of the external load in the numerical model defines the bearing locus direction, namely, if force is applied in vertical direction, so it will be the locus of the shaft. Consequently, the test rig is 
capable of evaluating the capacity of the model in representing the physical problem.

\section{RESULTS AND DISCUSSION}

\section{Comparison between theoretical and experimental results}

This section presents the validation of the numerical model for the tilting pad journal bearing by comparing the results with the experimental data acquired by Andersen [24]. The focus of the validation was the static and thermal properties of the bearing.

The pivot stiffness adopted here is based on the experimental tests made by Andersen [24] that accomplished a static test applying gradually increasing load on the system (Fig. 8(b)) and measuring the displacements in the end of the arm and in the two sensors positioned in both pads (Figs. 8 (a) and (b)) generating a curve with two linear parts, in which the angular coefficient gives the stiffness of the pivot in both pads of the bearing. Sequentially, averages for each load are estimated. As the stiffness value does not show expressive changes, an overall average is performed among all loading levels for each sensor location (on the pivot direction and in the arm end). Concluding, a final average is reached at $3 \cdot 10^{7} \mathrm{~N} / \mathrm{m}$. The preload assembly is $m_{p}=0.73$ and $h_{0}=$ $54 \mu \mathrm{m}$. Three cases of static force were tested: (1) $500 \mathrm{~N}$, (2) $700 \mathrm{~N}$ and (3) $900 \mathrm{~N}$. The pads inlet flow rate applied during the simulations was chosen based on the work of Varela [15] with the value of $0.000375 \mathrm{~m}^{3} / \mathrm{s}$.

Concerning the replacement temperature, the inlet temperature should be gradually increased in order to consider the heating of the replacement oil passing through the system and back into the storage tank with the rising of the rotation speed. The model starts with an inlet temperature of $30^{\circ} \mathrm{C}$ at $11 \mathrm{~Hz}$ and rose linearly up to $40^{\circ}$ 
$\mathrm{C}$ at the maximum rotation speed of $47 \mathrm{~Hz}$. These values were adopted based on the experimental observation of the test rig oil tank temperature.

The tests keep the static load at the end of the arm and the rotation speed increases to study the journal eccentricity ratio. To analyze the eccentricity, the Sommerfeld number is defined by Equation 19. In this equation, $\omega$ is the angular velocity of the journal measured in $[r p s]$ and $\mathrm{W}$ is the loading of the bearing in $[N]$.

$$
S=\frac{2 \mu L \omega R^{3}}{W(R s-R)^{2}}
$$

Figure 9 shows the experimental results at four different rotation speeds for the eccentricity ratio compared to the proposed theoretical model in the same range of rotation. It is important to point out that all critical conditions (lower velocities) for each load were tested (Table 2) and compared according to the Stribeck diagram (NguyenSchäfer [32]) being the $\lambda$ parameter far over the initial characteristic values for full film hydrodynamic lubrication $\left(\lambda=\frac{h_{\min }}{1.25 R_{a}}, R_{a}\right.$ is the average roughness of both contact surfaces). It is also interesting to observe that higher the load, lower the $\lambda$ factor as expected.

[Table 2]

[Figure 9]

Figure 9 shows that higher the loads higher the shaft eccentricities ratio, as expected. The model's results present a good agreement with experimental data, mainly for the high static load (larger relative errors for $500 \mathrm{~N}$, within $9 \%$ and $7 \%$, and minor relative errors for $700 \mathrm{~N}$, within $1 \%$ and 4\%). Experimental and model results present the same behavior of decreasing eccentricity ratio for higher rotation speeds. 
The following comparison (Figure 10) regards the oil film temperature at $75 \%$ of angular span of the pad. Using the temperature measurements from Andersen [24] (upper and lower pads), the numerical model results were obtained for the same range of rotation speed and the same load conditions: $500 \mathrm{~N}, 700 \mathrm{~N}$ and $900 \mathrm{~N}$. Results show a smooth variation with load and a stronger dependency with rotation speed. The numerical model achieved a good agreement with the experimental data. It is also possible to observe the temperature tendency to reaching similar values for both pads with the increasing of rotation. This phenomenon occurs due to the fact of with higher rotations the bearing tends to the center and the oil film thickness tends to be more similar between the pads, different from low-rotation cases in which the lower segment is more loaded and has a considerably lower film thickness.

[Figure 10]

Following, the simulation results analyze the pivot flexibility influence, namely, comparing simulations with and without the pivot stiffness, considering the parameter in oil film thickness and pressure distribution. All three load levels presented similar behavior and the medium load condition was selected $(700 \mathrm{~N})$.

Figure 11 shows the graphs of oil film thickness for the two pads simulated with $700 \mathrm{~N}$ and $11 \mathrm{~Hz}$ rotation speed. The Oil film thickness increases when the pivot stiffness is considered for both lower and upper pads. Pressure distribution showed in Figure 12 follows the expected pattern due to the increasing of oil film thickness, i.e., the pressure was reduced. 
The last parameter analyzed is the temperature profile on the oil film thickness for each pad. Figure 13 shows the temperature field over the oil film thickness (ydirection) and varying with the $\mathrm{x}$-direction for a middle point of $\mathrm{z}$-direction $(z=$ 20 volumes). The graphs show that temperature increases with the non-consideration of pivot flexibility, and the behavior is compatible with other parameters analyzed before. This occurs because with lower oil film thickness and higher pressure the temperature field tends to obtain higher temperature values. The main temperature differences were perceptive at the end of the pad, in the outlet of oil film, which contains the lower oil film thickness.

[Figure 11]

[Figure 12]

[Figure 13]

\section{CONCLUSIONS}

The first part of the results section presents the validation of the numerical results simulated for a tilting pad journal bearing in steady-state conditions and is performed based on the test rig designed for this purpose - presented in section 4 . We can affirm that the numerical results show good agreement regarding the oil film temperature of the pad, and the equilibrium position of the system.

The accuracy of the 3D approach for the THD model, considering pivot flexibility and discretization of oil film thickness for predicting the oil film forces and the equilibrium position of the rotor, provided good results when compared to the experimental tests under the same conditions. 
The comparisons showed, experimentally and numerically, that load increase caused a smooth variation of temperatures. The main differences in temperature, in the application presented here, are caused by rotational speed variations. On the other hand, some limitation in the experiments due to the replacement temperature in the oil reservoir hindered to carry them on high rotational speeds.

The pivot flexibility consideration, as observed in the results, is significant to achieve a good agreement between the theoretical model and experimental tests. An improved prediction of temperature field and, consequently, the viscosity of the oil film thickness and the estimation of the journal position over the range of rotation speeds, is essential to analyze TPJB and the system behavior where this mechanism is applied.

\section{ACKNOWLEDGMENTS}

The authors would like to thank CNPq, Fapesp Grants \#2015/20363-6 and \#2017/18629-3 and Petrobras Brazil for the financial support to this research. The authors also thank Espaço da Escrita - Pró-Reitoria de Pesquisa - UNICAMP - for the language services provided.

\section{REFERENCES}

[1] Pinkus, O. (1956), “Analysis of Elliptical Bearing”, Transactions of the ASME, Vol. 78, pp. 965-973.

[2] Fillon, M., Bligoud, J. C., Frene, J., (1992), "Experimental Study of Tilting-Pad Journal Bearings - Comparison with Theoretical Thermoelastohydrodynamic Results", ASME Journal of Tribology, Vol. 114, pp. 579-588.

[3] Fillon, M., Khonsari, M., (1996), “Thermohydrodynamic Design Charts for TiltingPad Journal Bearings", ASME Journal of Tribology, Vol. 118, pp.232-238.

[4] Tanaka, M. (2000), "Recent thermohydrodynamic analyses and designs of thick-film bearings", Proc. IMechE Part J: J. Eng. Tribol, 214, pp. 107-122. 
[5] Chang, Q., Yang, P., Meng, Y., Wen, S., (2002), “Thermoelastohydrodynamic analysis of the static performance of tilting pad journal bearings with NewtonRaphson method”, Tribology International, 35, pp. 225-234.

[6] Dowson, D., (1962), “A Generalized Reynolds Equation for Fluid Film Lubrication", International Journal of Mechanical Sciences, Volume 4, Issues 2, pp. 159-170.

[7] Dowson, D., Hudson, J. D., Hunter, B., March, C. N., (1966), “An Experimental Investigation of the Thermal Equilibrium of Steadily Loaded Journal Bearings", Proc. Institution of Mechanical Engineers, 181, Part 3B, pp.70-80.

[8] Heshmat, H., Pinkus, O., (1986), “Mixing Inlet Temperatures in Hydrodynamic Bearings", Journal of Tribology, v.108, pp.231-248.

[9] Han, T., Paranjpe, R. S. (1990), “A Finite Volume Analysis of the Thermohydrodynamic Performance of Finite Journal Bearing”, Journal of Tribology, v.112, pp.557-566, 162.

[10] Dimond, T., Younan, A., Allaire, P., (2011), “A Review of Tilting Pad Bearing Theory", International Journal of Rotating Machinery, Vol. 2011, 23 p.

[11] Santos, M. F., (1997), "Efeitos Térmicos em Mancais Segmentados”, Master Thesis, University of Campinas, Campinas, Brazil.

[12] Santos, I. F., Nicoletti, R., (1999), “THD analysis in tilting-pad journal bearings using multiple orifice hybrid lubrication”, ASME Journal of Tribology, 121, pp. 892-900.

[13] Daniel, G.B., Cavalca, K. L, (2012), "Investigation of the influence of thermal effects in the dynamic coefficients of a tilting pad journal bearing", In 10th International Conference on Vibrations in Rotating Machinery, edited by IMechE, Woodhead Publishing, Pages 479-489.

[14] Daniel, G. B., Cavalca, K. L., (2013), "Evaluation of the Thermal Effects in Tilting Pad Bearing,” International Journal of Rotating Machinery, vol. 2013, Article ID 725268, 17 pages, 2013.

[15] Varela, A., Santos, F. I., (2014), “Tilting-Pad Journal Bearings with Active Lubrication Applied as Calibrated Shakers: Theory and Experiment”. ASME. J. Vib. Acoust, 136(6):061010-061010-11. doi:10.1115/1.4028452.

[16] Nielsen, B. B., (2010), “Creation of a Mechatronic Tilting Pad Test Rig”, Master Thesis, Technical University of Denmark, Denmark. 
[17] Nilsson, L. R. K., (1978), "The Influence of Bearing Flexibility on the Dynamic Performance of Radial Oil Film Bearings," Proceedings of the Fifth Leeds- Lyon Symposium on Tribology, pp. 311-319.

[18] San Andrés, L., and Tao, Y., (2013), "The Role of Pivot Stiffness on the Dynamic Force Coefficients of Tilting Pad Journal Bearings,” ASME J. Eng. Gas Turbines Power, 135, pp. 112505.

[19] San Andrés, L., Tao, Y., and Li, Y., (2014), “Tilting Pad Journal Bearing: On Bridging the Hot Gap Between Experimental Results and Model Predictions," ASME J. Eng. Gas Turbines Power, 137, pp.022505.

[20] Gaines, J., (2014), "Examining the Impact of Pad Flexibility on the Rotordynamic Coefficients of Rocker-Pivot-Pad Tiling-Pad Journal Bearings,” Master Thesis, Mechanical Engineering, Texas A\&M University, College Station, TX.

[21] Suh, J., Choi, Y.-S, . Pivot design and angular misalignment effects on tilting pad journal bearing characteristics: Four pads for load on pad configuration, Tribology International, 2016, v. 102, p. 580-599.

[22] Conti, R., Frilli, A., Galardi, E., Meli, E., Nocciolini, D., Pugi, L., Rindi, A., Rossin, S. (2016), “An efficient quasi-3D rotordynamic and fluid dynamic model of Tilting Pad Journal Bearing”, Tribology International,Vol. 103, 2016, pp. 449-464.

[23] Pedersen, T. G., (2016), "Active control force in fluid film bearings - An experimental parameter study", Master Thesis, Technical University of Denmark, 2016.

[24] Andersen, T. B., (2017), “Two Different Design Solutions to Adjust the Properties of Tilting-Pad Journal Bearings - An Experimental Investigation", Master Thesis, Technical University of Denmark.

[25] Reynolds, O., (1886), "On the Theory of Lubrication and its Application to Mr. Beauchamp Tower's Experiments, including an Experimental Determination of the Viscosity of Olive Oil". Philosophical Transactions of Royal Society of London, Series A, Vol. 177, Part 1, pp.157-234.

[26] Santos, I. F., Russo, F. H., (1996), “Tilting-pad journal bearing with electronic radial oil injection", ASME/STLE Tribology Conference, San Francisco-USA, $11-15$. 
[27] Cameron, A., (1951), "Heat Transfer in Journal Bearings: A Preliminary Investigation", Proceedings of the 1951 general Discussion on Heat Transfer, Inst. Mech. Engr., pp. 194-197.

[28] Walther, C., Erdöl und Teer. 7 (1931) 382.

[29] Walther, C., Maschinenbau. 10 (1931) 670.

[30] Patankar, S. V., (1980), "Numerical Heat Transfer and Fluid Flow”, Taylor \& Francis.

[31] Bizarre, L. (2019), "Modelo de lubrificação THD para mancais segmentados considerando a direção da espessura de filme e alimentação - Teoria e Experimento", Doctoral Thesis, University of Campinas, Department of Integrated Systems, Campinas, Brazil.

[32] Nguyen-Schäfer, H. “Computational Design of Rolling Bearings”. Cham: Springer International Publishing, (2016). 
Table 1. Dimensions and parameters of tilting pad bearing, journal and frame.

Table 2. The $\lambda$ parameter of Stribeck curve for the critical conditions.

Figure 1. (a) and (b) Representation of the journal tilting pad bearing geometry and reference systems applied to describe the dynamics of the tilting pad journal bearing and (c) Eccentricity scheme.

Figure 2. Pivot stiffness representation in the tilting pad bearing system.

Figure 3. (a) Transformation from physical to numerical domain representation, (b) Oil film boundary conditions scheme.

Figure 4. Flowchart of the numerical iterative process adapted from Daniel \& Cavalca $[13,14]$.

Figure 5. (a) Processing time with the increasing of volumes discretization and (b) eccentricity ratio convergence with the increasing of volumes discretization.

Figure 6. (a) Scheme of energy equation integration: for each value of $z$, a complete mesh in $\boldsymbol{x} \times \boldsymbol{y}$ is evaluated. (b) Mixture representation between the heat flux income from the previous pad, the replacement oil and the oil flux on the inlet of the next pad.

Figure 7. Assembled test rig for tilting pad bearing tests. The items labeled on the figure are: (1) Frame, (2) Electromagnetic shaker (B\&K 4384), (3) Dynamic force transducer (B\&K 8230-002), (4) signal conditioner for (3) (Manfred Weber M68D1), (5) amplifier for shaker (B\&K 2706), (6) static force transducer (HMB U9B), (7) electrical motor, (8) remote control for electrical motor, (9) tachometer, (10) displacement sensor at free extremity (MICRO-EPSILONeddyNCDT 3010-M-s2), (11) displacement sensors at journal (Pulsotronic KJ2-M8MB40), (16) Servovalve (MOOG D765-231), (17) oil filter, (18) high pressure line for upper pad, (19) high pressure line for lower pad, (20) low pressure supply, (21) low pressure suction and (22) acquisition and command unit (DSpace 1104), Andersen [24].

Figure 8. (a) Schematic setup of the test rig operational principle. (b) A mechanical model of the test rig adapted from Andersen [24]. 
Figure 9. Experimental results (Andersen [24]) of eccentricity ratio versus Sommerfeld number compared to the theoretical model (numerical simulations): (a) $500 \mathrm{~N}$, (b) 700 $\mathrm{N},(\mathrm{c}) 900 \mathrm{~N}$.

Figure 10. Experimental results of temperature versus rotational speed (Andersen [24]) compared to the theoretical model results of this research: (a) $500 \mathrm{~N}$, (b) $700 \mathrm{~N}$ and (c) $900 \mathrm{~N}$.

Figure 11. Numerical results of oil film thickness over the $\mathrm{x}$-direction represented by volumes discretization and considering the first rotation simulated for the $700 \mathrm{~N}$ load (11 Hz rotation). (a) Without pivot flexibility and (b) With $K_{\text {pivot }}=3.10^{7} \mathrm{~N} / \mathrm{m}$.

Figure 12. Numerical results of pressure distribution over the $\mathrm{x}$-direction represented by volumes discretization and considering the first rotation simulated for the $700 \mathrm{~N}$ load (11 Hz rotation) with and without pivot stiffness. (a) Upper pad and (b) Lower pad under, without pivot flexibility; (c) Upper pad and (d) Lower pad, with $K_{\text {pivot }}=$ $3 \cdot 10^{7} \mathrm{~N} / \mathrm{m}$.

Figure 13. Numerical results of temperature over the $\mathrm{x}$-direction for a middle section in the $\mathrm{z}$-direction and considering the first rotation simulated for the $700 \mathrm{~N}$ load $(11 \mathrm{~Hz}$ rotation). (a) Upper pad and (b) Lower pad, without pivot flexibility; (c) Upper pad and (d) Lower pad, with $K_{\text {pivot }}=3 \cdot 10^{7} \mathrm{~N} / \mathrm{m}$. 
Table 1. Dimensions and parameters of tilting pad bearing, journal and frame

\begin{tabular}{cccc}
\hline & Symbol & Value & Unit \\
\hline Journal radius & $R$ & 49.692 & {$[\mathrm{~mm}]$} \\
Bearing length & $L$ & 100 & {$[\mathrm{~mm}]$} \\
Number of pads & - & 2 & - \\
Pad radius & $R_{s}$ & 49.892 & {$[\mathrm{~mm}]$} \\
Pad angular span & $\beta$ & 69 & {$\left[{ }^{\circ}\right]$} \\
Pad thickness & $h_{s}$ & 12 & {$[\mathrm{~mm}]$} \\
Pad mass & $m_{p a d}$ & 0.72 & {$[\mathrm{~kg}]$} \\
Load angle & - & On Pad & - \\
Pivot offset & - & 0.5 & - \\
Distance to the journal center & $l_{1}$ & 0.21 & {$[\mathrm{~mm}]$} \\
Distance to end of the frame & $l_{2}$ & 0.47 & {$[\mathrm{~mm}]$} \\
Mass of frame and journal & $m$ & 18.54 & {$[\mathrm{~kg}]$} \\
Oil type & - & ISO & - \\
Pad material & & VG22 & - \\
Pivot material & - & Brass & - \\
Thermal conductivity & - & Steel & - \\
Oil specific heat capacity & $k_{f}$ & 0.132 & {$[\mathrm{~W} /(\mathrm{m} \mathrm{K})]$} \\
Preload & $C_{f}$ & 1962 & {$[\mathrm{~J} /(\mathrm{Kg} \mathrm{K})]$} \\
Oil film density & $m_{p}$ & 0.73 & - \\
Shaft temperature & $\rho$ & 879 & {$\left[\mathrm{Kg} / \mathrm{m}^{3}\right]$} \\
Radial clearance & $T_{\text {shaft }}$ & 43 & {$\left[{ }^{\circ}\right]$} \\
& $C_{b}$ & 50 & {$[\mu \mathrm{mm}]$} \\
\hline
\end{tabular}

Table 2. The $\lambda$ parameter of Stribeck curve for the critical conditions.

\begin{tabular}{cccc}
\hline & $\mathbf{5 0 0} \mathbf{~ N}$ & $\mathbf{7 0 0} \mathbf{~ N}$ & $\mathbf{9 0 0} \mathbf{~ N}$ \\
\hline Minimum oil film thickness for the lower pad $[\mu \mathrm{m}]$ & 57.0 & 54.1 & 50.1 \\
Surface arithmetic average roughness $[\mu \mathrm{m}]$ & 0.25 & 0.25 & 0.25 \\
Rotation speed $[\mathrm{Hz}]$ & 11 & 11 & 11 \\
$\lambda[-]$ & 182.3 & 173.0 & 160.4 \\
\hline
\end{tabular}




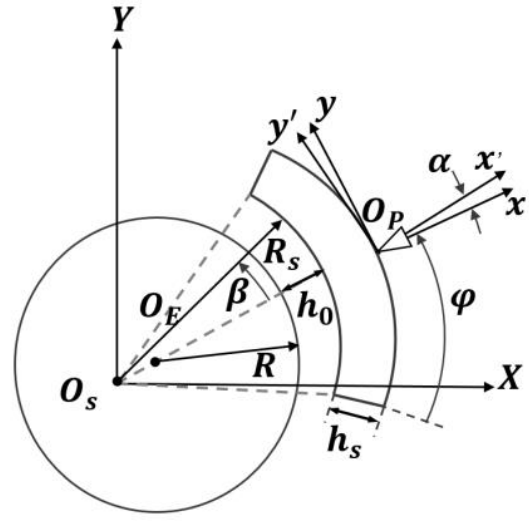

(a)

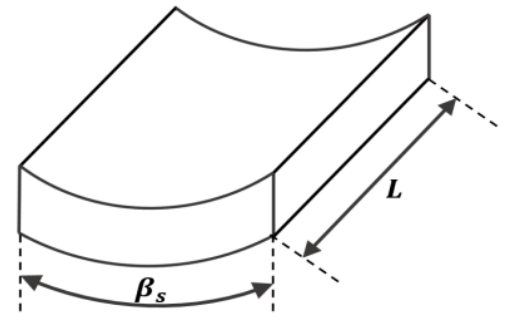

(b)

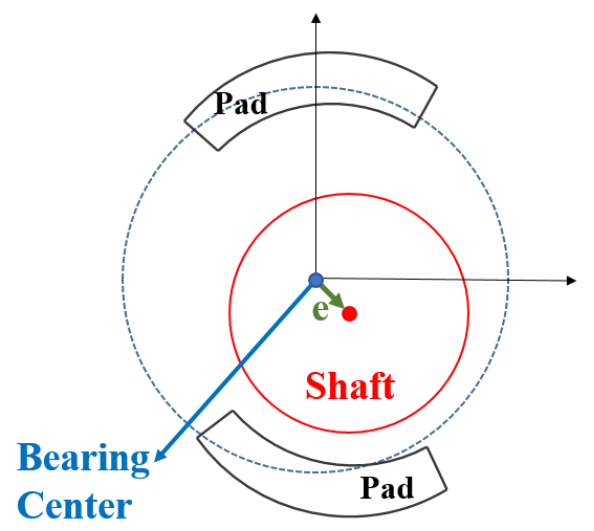

(c)

Figure 1 - (a) and (b) Representation of the journal tilting pad bearing geometry and reference systems applied to describe the dynamics of the tilting pad journal bearing and (c) Eccentricity scheme.

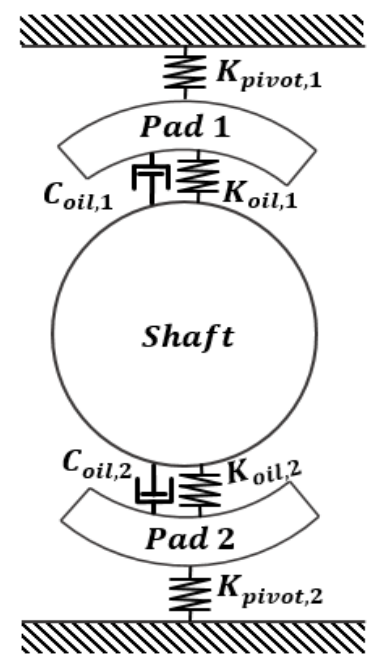

Figure 2. Pivot stiffness representation in the tilting pad bearing system. 


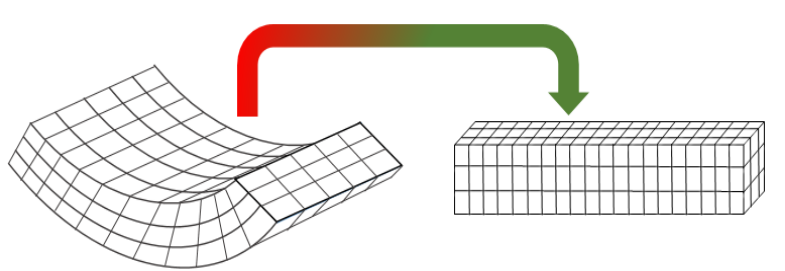

(a)

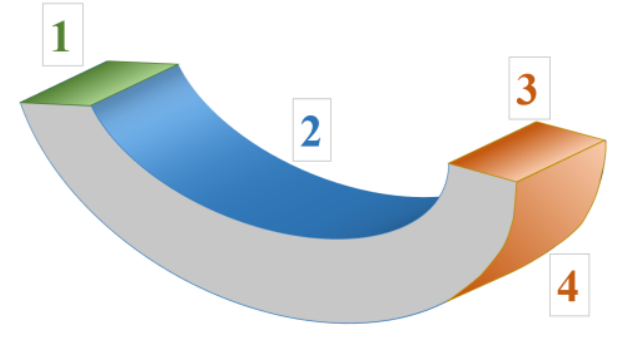

(b)

Figure 3. (a) Transformation from physical to numerical domain representation. (b) Oil film boundary conditions scheme.

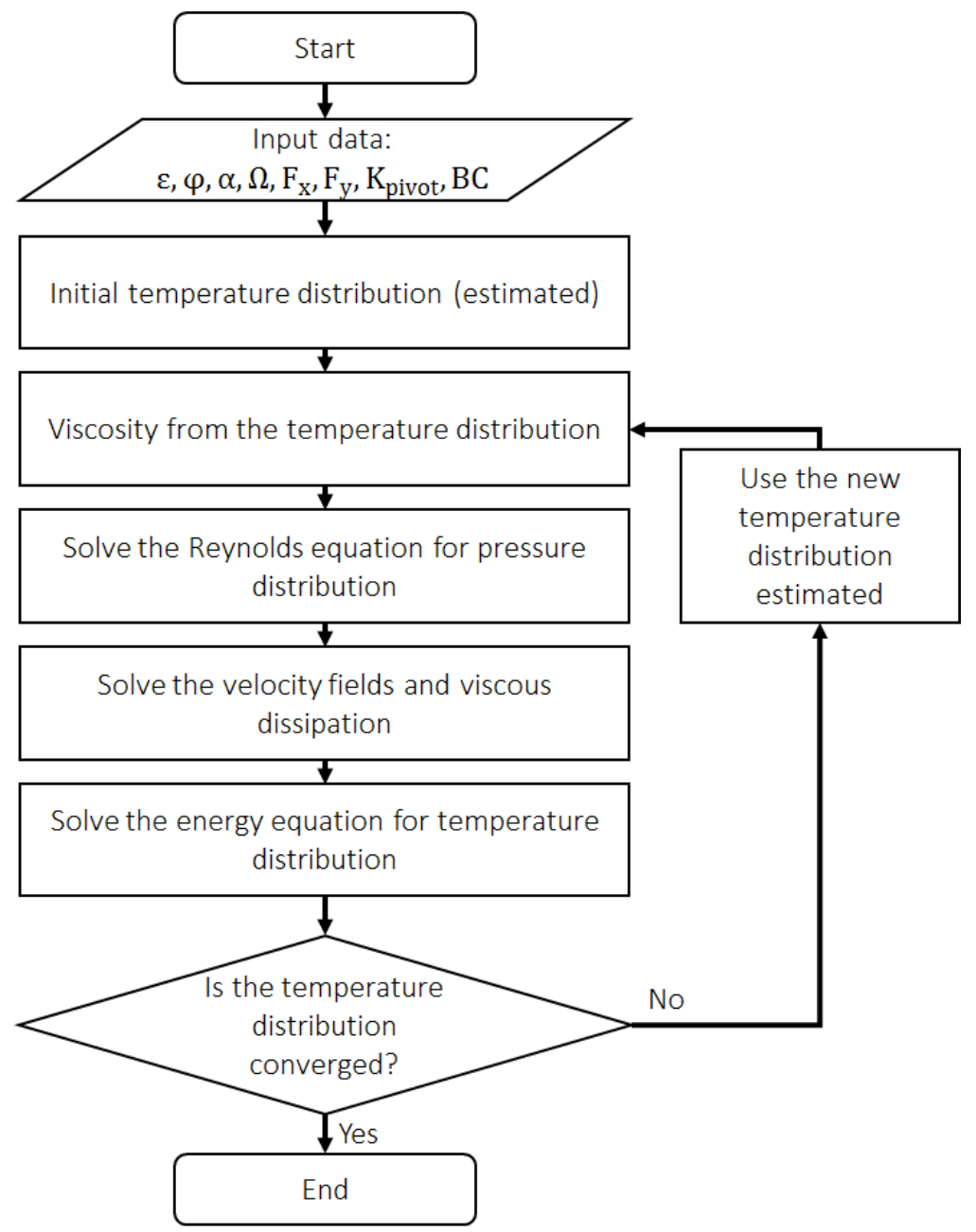

Figure 4. Flowchart of the numerical iterative process adapted from Daniel \& Cavalca $[13,14]$. 


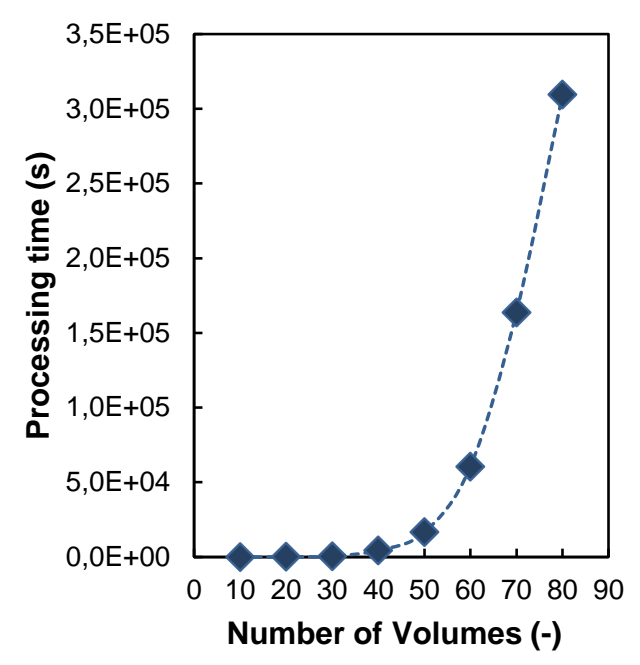

(a)

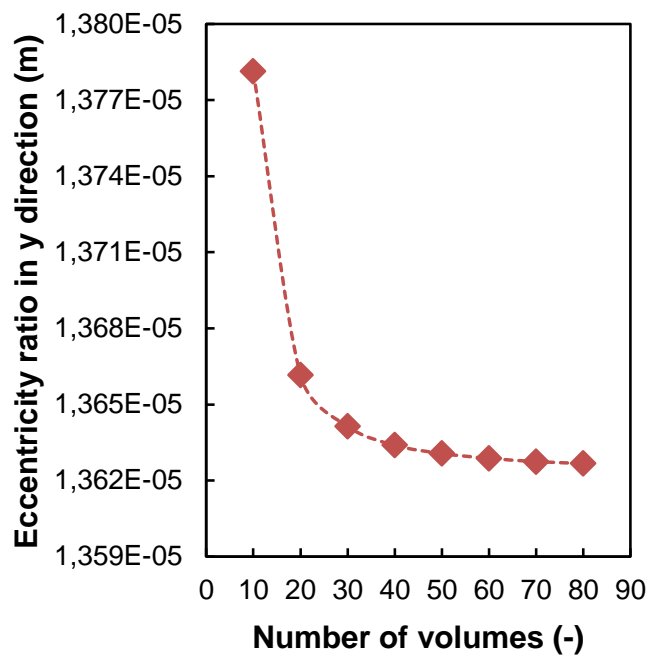

(b)

Figure 5. (a) Processing time with the increasing of volumes discretization and (b) eccentricity ratio convergence with the increasing of volumes discretization.

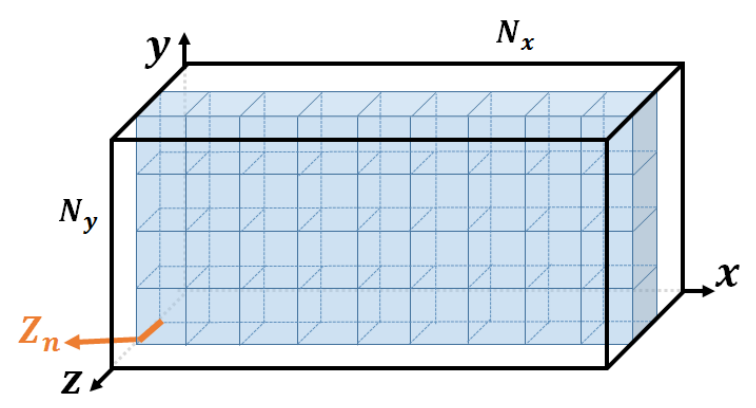

(a)

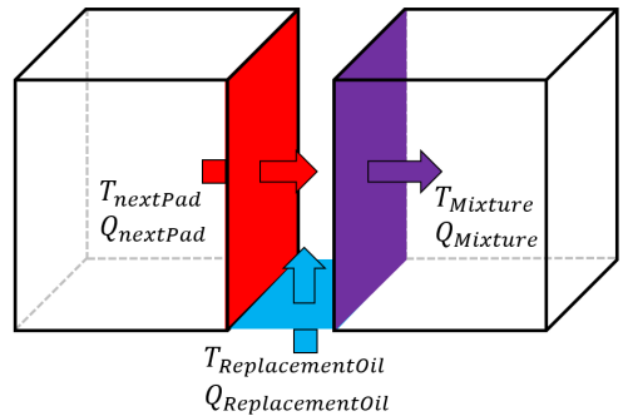

(b)

Figure 6. (a) Scheme of energy equation integration: for each value of $z$, a complete mesh in $x \times y$ is evaluated. (b) Mixture representation between the heat flux income from the previous pad, the replacement oil and the oil flux on the inlet of the next pad. 


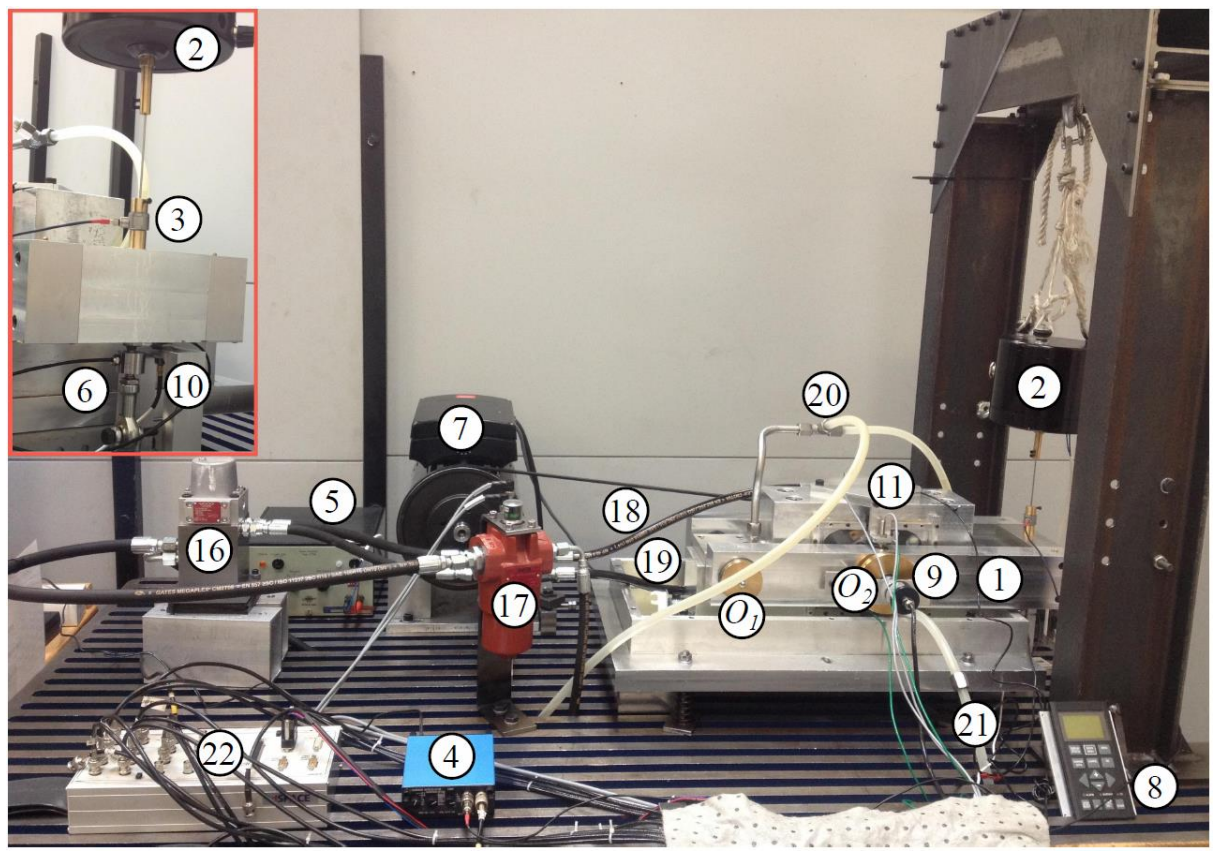

Figure 7. Assembled test rig for tilting pad bearing tests. The items labeled on the figure are: (1) Frame, (2) Electromagnetic shaker (B\&K 4384), (3) Dynamic force transducer (B\&K 8230-002), (4) signal conditioner for (3) (Manfred Weber M68D1), (5) amplifier for shaker (B\&K 2706), (6) static force transducer (HMB U9B), (7) electrical motor, (8) remote control for electrical motor, (9) tachometer, (10) displacement sensor at free extremity (MICRO-EPSILONeddyNCDT 3010-M-s2), (11) displacement sensors at journal (Pulsotronic KJ2-M8MB40), (16) Servovalve (MOOG D765-231), (17) oil filter, (18) high pressure line for upper pad, (19) high pressure line for lower pad, (20) low pressure supply, (21) low pressure suction and (22) acquisition and command unit (DSpace 1104), Andersen [24].

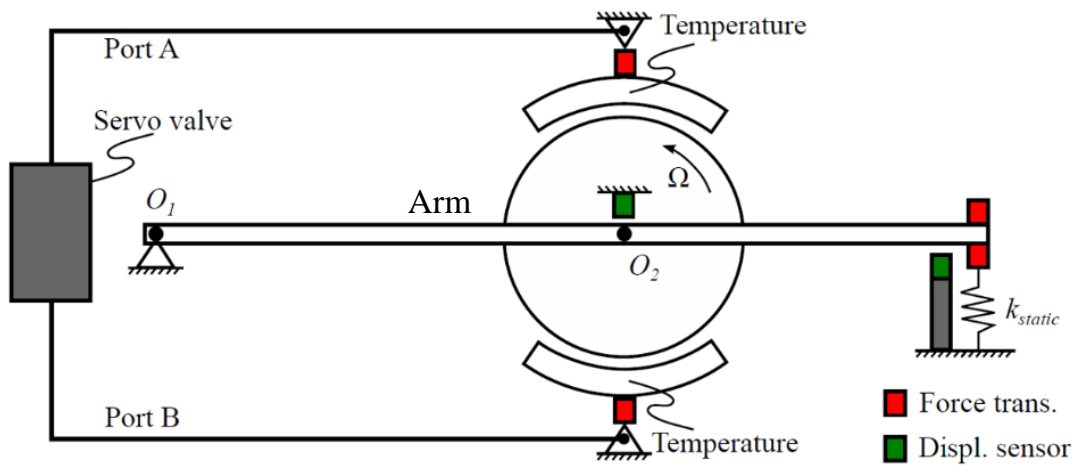

(a) 


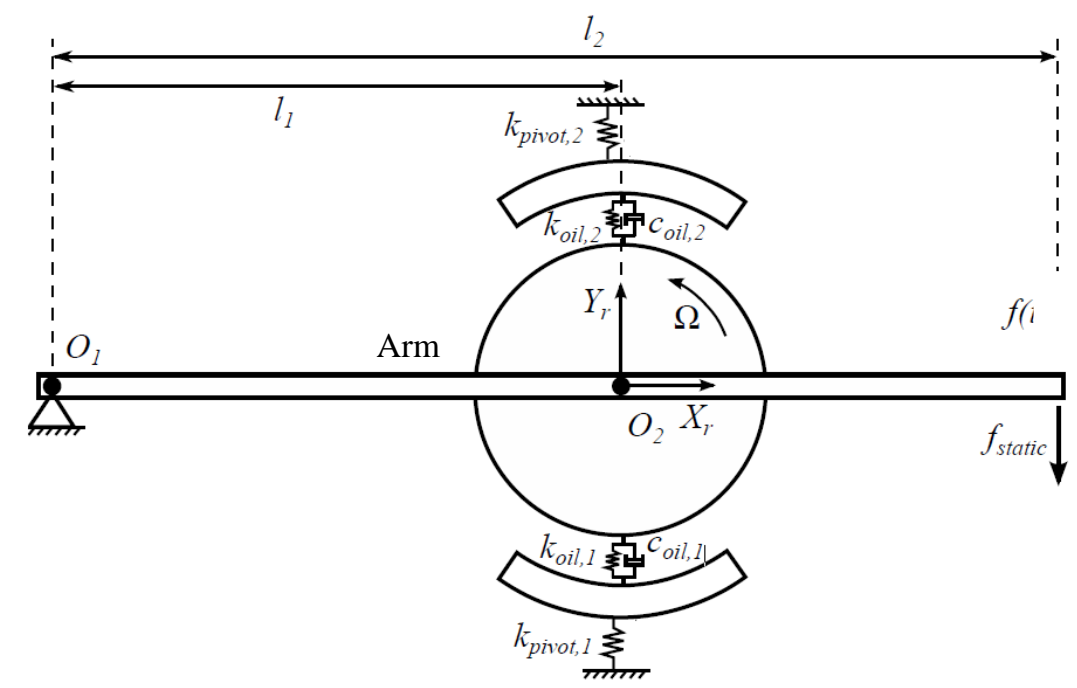

(b)

Figure 8. (a) Schematic setup of the test rig operational principle. (b) A mechanical model of the test rig adapted from Andersen [24].

$500 \mathrm{~N}$

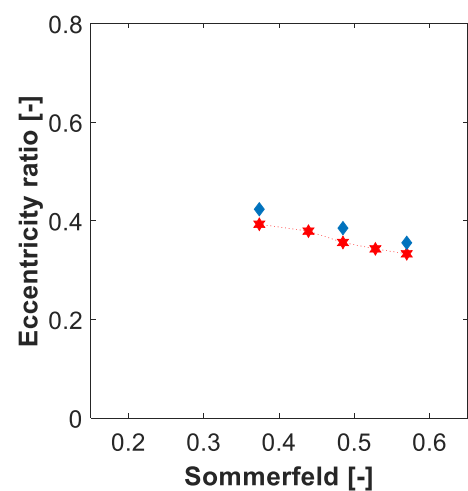

(a)
$700 \mathrm{~N}$

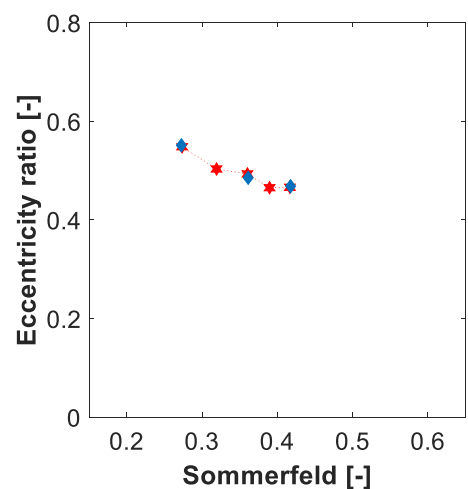

(b)

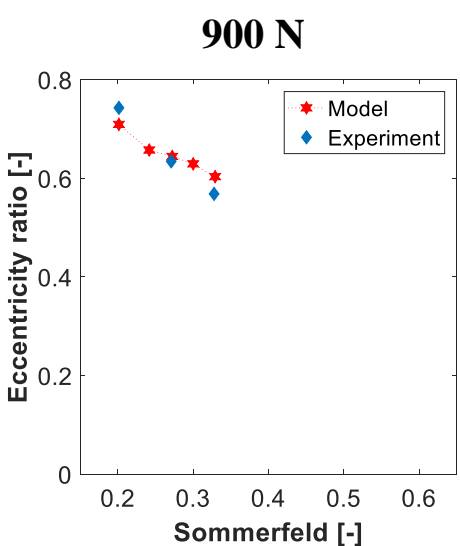

(c)

Figure 9. Experimental results (Andersen [24]) of eccentricity ratio versus Sommerfeld number compared to the theoretical model (numerical simulations): (a) $500 \mathrm{~N}$, (b) 700 $\mathrm{N}$, (c) $900 \mathrm{~N}$. 
$500 \mathrm{~N}$

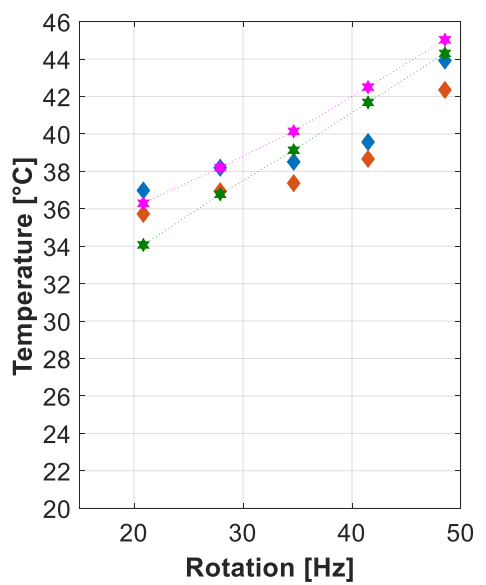

(a)
$700 \mathrm{~N}$

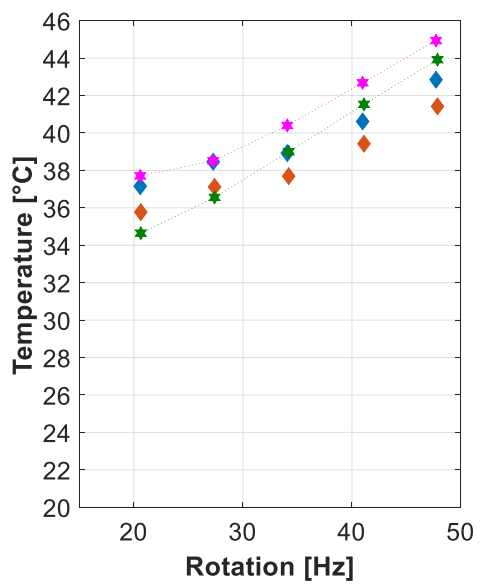

(b)

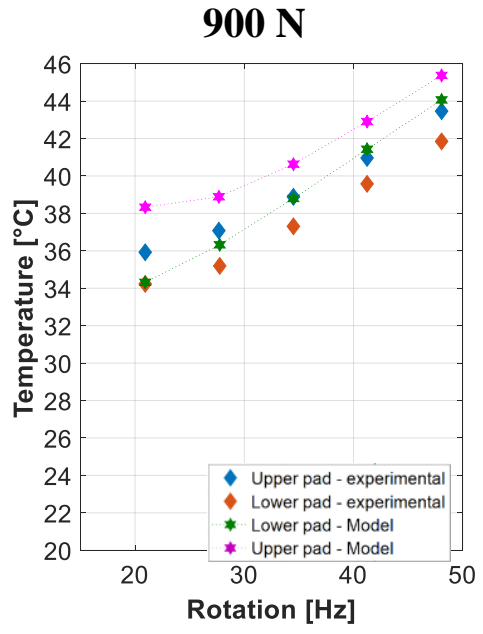

(c)

Figure 10. Experimental results of temperature versus rotational speed (Andersen [24]) compared to the theoretical model results of this research: (a) $500 \mathrm{~N}$; (b) $700 \mathrm{~N}$ and (c) $900 \mathrm{~N}$.

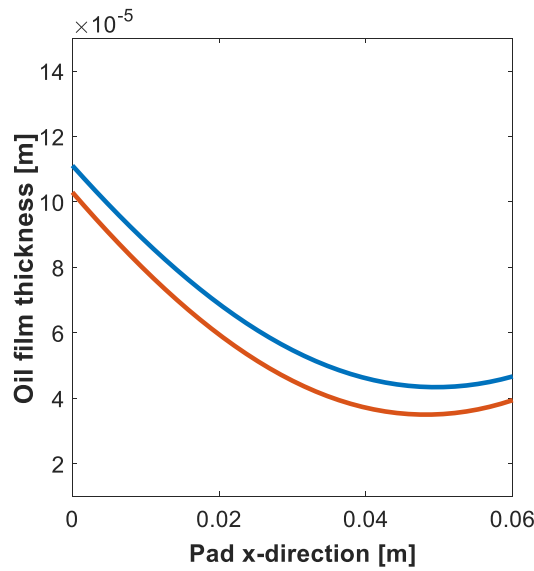

(a)

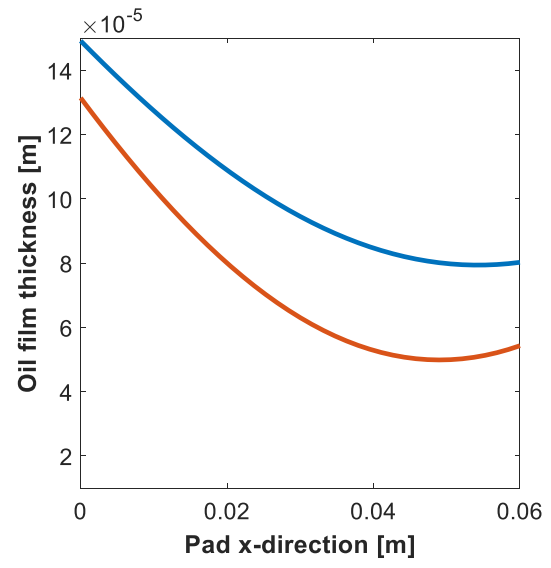

(b)

Figure 11. Numerical results of oil film thickness over the x-direction represented by volumes discretization and considering the first rotation simulated for the $700 \mathrm{~N}$ load (11 $\mathrm{Hz}$ rotation). (a) Without pivot flexibility and (b) With $K_{\text {pivot }}=3.10^{7} \mathrm{~N} / \mathrm{m}$. 


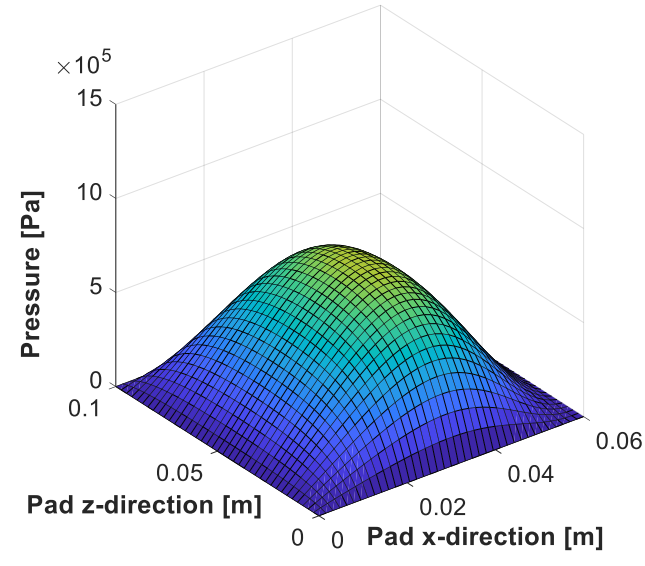

(a)

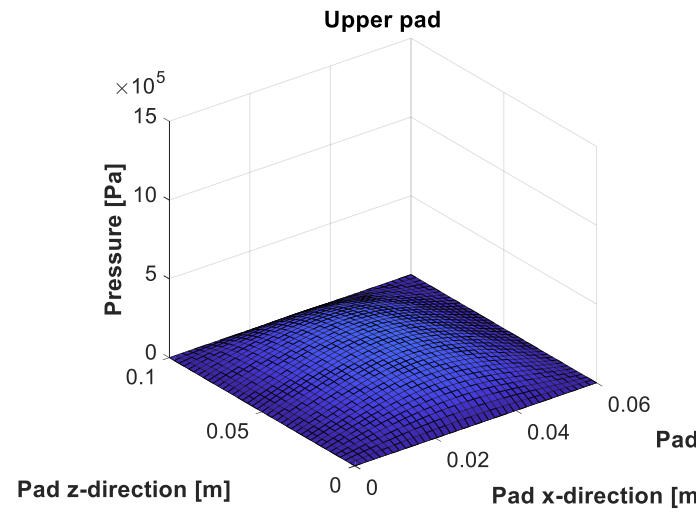

(c)

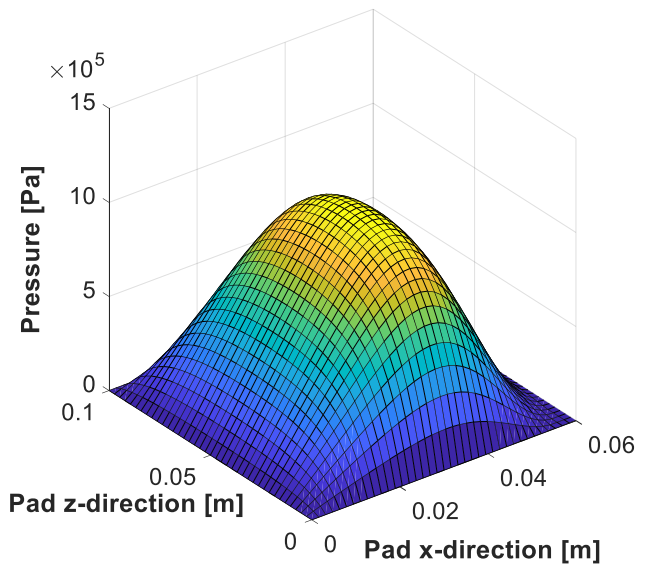

(b)

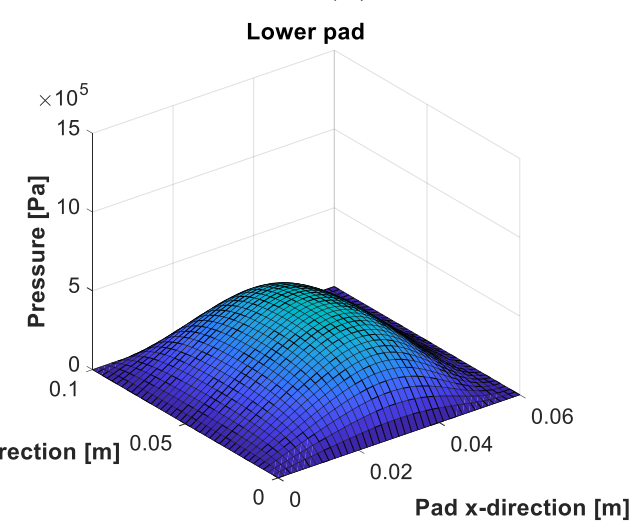

(d)

Figure 12. Numerical results of pressure distribution over the $\mathrm{x}$-direction represented by volumes discretization and considering the first rotation simulated for the $700 \mathrm{~N}$ load (11 Hz rotation) with and without pivot stiffness. (a) Upper pad and (b) Lower pad under, without pivot flexibility; (c) Upper pad and (d) Lower pad, with $K_{\text {pivot }}=$ $3 \cdot 10^{7} \mathrm{~N} / \mathrm{m}$.

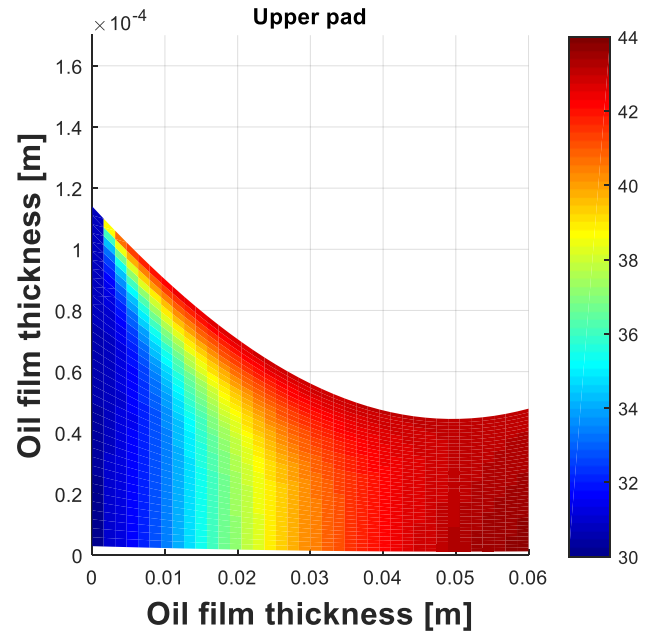

(a)

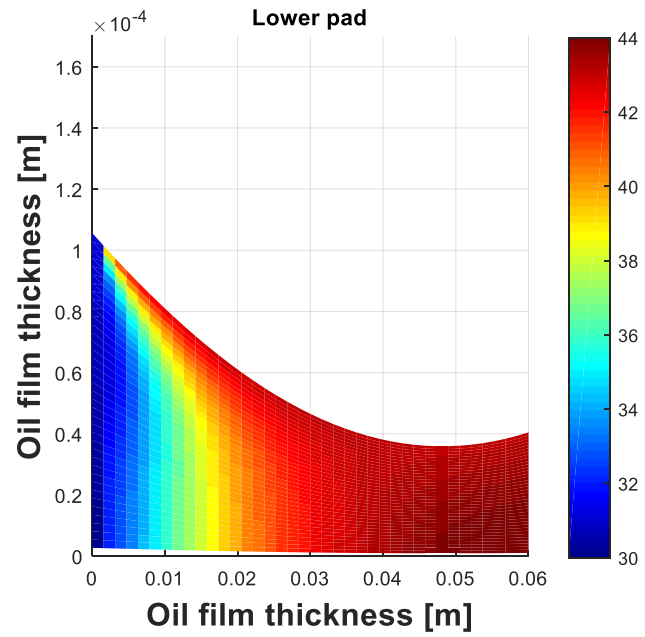

(b) 


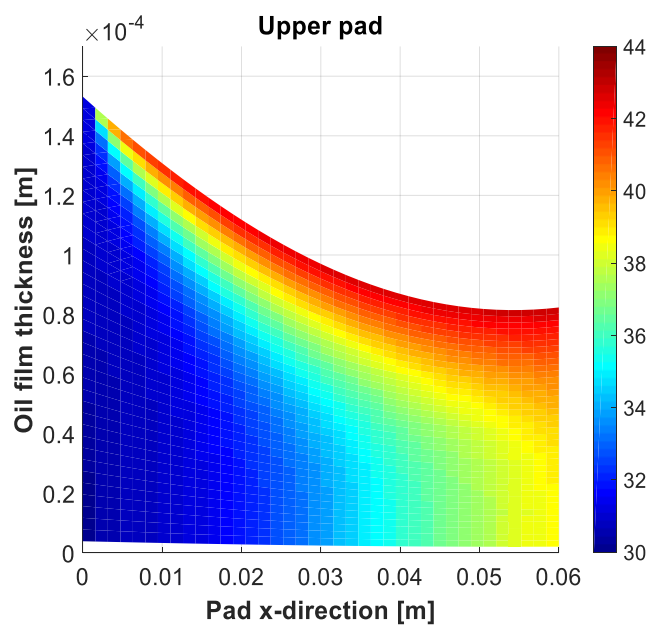

(c)

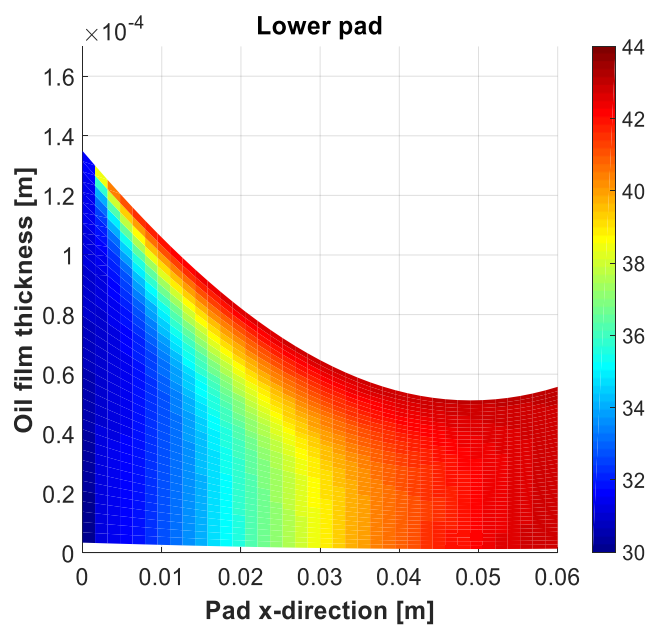

(d)

Figure 13. Numerical results of temperature over the $\mathrm{x}$-direction for a middle section in z-direction and considering the first rotation simulated for the $700 \mathrm{~N}$ load $(11 \mathrm{~Hz}$ rotation). (a) Upper pad and (b) Lower pad, without pivot flexibility; (c) Upper pad and (d) Lower pad, with $K_{\text {pivot }}=3 \cdot 10^{7} \mathrm{~N} / \mathrm{m}$. 